\title{
Role of Protease-Activated Receptor 2 in Regulating Focal Segmental Glomerulosclerosis
}

\author{
Yongjun Wang ${ }^{a}$ Yanfa He ${ }^{b}$ Mingzheng Wang ${ }^{c}$ Pei Lv ${ }^{d} \quad J u n x i a$ Wang ${ }^{e}$ \\ Jianzhen Liu \\ ${ }^{a}$ Department of Cardiovascular Medicine, bepartment of Cardiac Surgery, 'Department of Thoracic

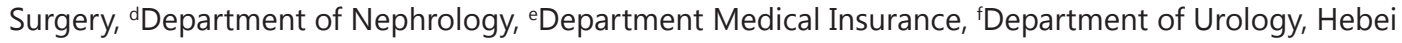 \\ Chest Hospital, Shijiazhuang, Hebei, China
}

\section{Key Words}

PAR2 • Renal fibrosis • Pro-inflammatory cytokines • TGF- $\beta 1$

\begin{abstract}
Background/Aims: The underlying mechanisms leading to focal segmental glomerulosclerosis (FSGS) are lacking. In this report, we examined the role of protease-activated receptors (PARs) subtype PAR2 and its downstream signals in regulating the pathophysiological process of FSGS. Methods: Nephropathy was induced by intravenous injections of adriamycin (ADR) in rats to study FSGS. Western Blot analysis and ELISA were employed to determine the protein expression levels of PAR2 and its downstream signal pathways as well as the levels of PICs. Results: In ADR rats, expression of PAR2, PKC $\varepsilon$ and PKA was amplified and this was accompanied with increases of pro-inflammatory cytokines (PICs) including IL-1 $\beta$, IL- 6 and TNF- $\alpha$. Inhibition of PAR2 signal by systemic administration of FSLLRY-NH2 (FSL) attenuated amplification of PICs. Notably, FSL further influenced key molecular mediators during development of FSGS. i.e., it specifically restored the impaired nephrin and attenuated the exaggerated transforming growth factor beta 1 (TGF- $\beta 1$ ), caspase- 9 and desmin thereby improving worsened renal functions and glomerular injury. Consistent with this, in cultured podocytes FSL also largely restored downregulation of nephrin and attenuated amplifications of caspase- 9 and desmin induced by TGF- $\beta 1$. Conclusions: Results of this study suggest that PAR2 plays an important role in mediating renal injury induced by glomerulosclerosis. Inhibition of PAR2 signal pathway has a protective effect on FSGS mainly via PIC and TGF- $\beta 1$ mechanisms. Targeting one or more of these signaling molecules may present new opportunities for treatment and management of FSGS observed in patients.

\section{Introduction}

Renal fibrosis is characterized by a number of distinct changes including glomerulosclerosis, interstitial fibrosis, tubular atrophy, peritubular capillary loss, and inflammation Y. Wang and Y. He made equal contributions to this work 
[1]. These insults can initiate fibrosis, such as epithelial injury, persistent inflammation, or progressive capillary loss [2]. Therapy for renal fibrosis remains somewhat problematic, partly due to the underlying mechanisms of these diseases are lacking. Apparently, animal models offer a better opportunity to study the mechanisms at cellular and molecular levels [3]. Among several models, nephropathy induced by intravenous injections of adriamycin (ADR) in rats has been widely used to study focal segmental glomerulosclerosis (FSGS) that is observed in patients, and this model is considered as an analogue of human FSGS $[2,3]$.

Protease-activated receptors (PARs) are a family member of G-protein-coupled receptors and are activated by a proteolytic mechanism [4]. Among the four members of PARs, PAR2 is largely distributed in various tissues including cardiovascular, respiratory, renal, gastrointestinal and liver systems [4]. Extracellular serine proteases, such as trypsin, tryptase, tissue factor VIIa, and kallikreins, activate PAR2, and thus the receptors are $\mathrm{N}$-terminally truncated by proteases to enable coupling and activation of intracellular G-protein signaling cascades [5]. Although serine proteases activate PAR2, several members of the serine protease family, including neutrophil elastase, cathepsin $\mathrm{G}$, and proteinase 3, have been shown to inactivate PAR2 by cleaving downstream of the tethered ligand $[6,7]$. PAR2 activation is generally pro-inflammatory both in vitro and in vivo [5].

Also, PAR2 is known to be coupled to Gq/11 and its activation leads to the activation of PLC $\beta$ and its downstream pathway PKC [4]. Also, PKA pathway is likely to be engaged in the role played by PAR2 [4]. Nonetheless, little is known about how PAR2 signal influences the pathophysiological process of FSGS. Thus, we hypothesized that PAR2 and its downstream signal pathways (i.e., PKCE and PKA) contribute to FSGS and blocking PAR2 signaling by systemic administration of FSLLRY-NH2 (FSL) attenuates pro-inflammatory cytokines (PICs), namely IL-1 $\beta$, IL- 6 and TNF- $\alpha$. We further hypothesized that blocking PAR2 improves key molecular mediators during development of FSGS, specifically impaired nephrin as well as the exaggerated transforming growth factor beta 1 (TGF- $\beta 1$ ), caspase- 9 and desmin and thereby largely recovers worsened renal functions and structures.

\section{Materials and Methods}

\section{Animals}

All experimental procedures were in accordance with the guidelines of the International Association for the Study of Pain and were approved by the Animal Research Committee of our institution. Male Sprague-Dawley rats weighing 180-200 g were used in this study. A rat model of nephropathy was induced by intravenous injections of ADR ( $4 \mathrm{mg} / \mathrm{kg}$ at the first week and $2 \mathrm{mg} / \mathrm{kg}$ at the fourth week; $\mathrm{n}=15$ ) after the right kidney was extirpated as described previously [8]. Age- and body weight-matched rats with shamoperation and saline injection were used as controls $(n=15)$. In additional group, FSL was given in ADR rats $(1 \mathrm{mg} / \mathrm{kg} /$ day, i.p., 6 weeks; $\mathrm{n}=20)$. Urine samples were collected before the surgery and at the end of each week. Then, urinary protein concentrations were determined by colorimetric assay (Bio-Rad) using bovine serum albumin (BSA) as the standard. Proteinuria was confirmed by urinary protein concentrations in samples. At the end of the sixth week rats were sacrificed. Then, blood samples were collected, and the kidney was removed and weighted for biochemical measurements.

Podocyte culture and treatment

Conditionally immortalized mouse podocyte cells were maintained at $33^{\circ} \mathrm{C}$ for proliferation in RPMI 1640 containing 10\% fetal bovine serum (Gibco) and 10U/ml of recombinant mouse $\gamma$-interferon (Invitrogen). They were then moved to $37^{\circ} \mathrm{C}$ for differentiation and cultured without $\gamma$-interferon. When they grew to about $80 \%$ confluence, podocytes were treated without treatment as control; and with $6 \mathrm{ng} /$ $\mathrm{ml}$ of TGF- $\beta 1$ (Invitrogen) in serum-free medium and incubated with FSL $(0.5 \mu \mathrm{g} / \mathrm{ml})$ and they were then moved to $37^{\circ} \mathrm{C}$ and treated with $6 \mathrm{ng} / \mathrm{ml}$ of TGF- $\beta 1$ for 48 hours. Thus, the cultured podocytes were divided as control; TGF- $\beta 1$-treatment; TGF- $\beta 1$-treatment with FSL.

\section{KARGER}




\section{Cellular Physiology Cell Physiol Biochem 2017;41:1147-1155 \begin{tabular}{ll|l|l|l|l} 
DOI: 10.1159/000464121 2017 The Author(s). Published by S. Karger AG, Basel \\
and Biochemistry
\end{tabular}}

Wang et al.: PAR2 Signaling and Renal Fibrosis

\section{Western Blotting analysis}

Total protein in tissue and in cells was extracted cells was extracted by homogenizing sample in ice-cold immunoprecipitation assay buffer with protease inhibitor cocktail kit (Roche). The lysates were centrifuged and the supernatants were collected for measurements of protein concentrations using a bicinchoninic acid assay reagent kit. Fifty microgram of total protein was loaded to run $7.5 \%$ or $10 \%$ sodium dodecyl sulfate-polyacrylamide gel electrophoresis (SDS-PAGE), and the protein was transferred to nitrocellulose membranes (GE Healthcare Biosci). Then, the membranes were incubated for 30 minutes in 5\% low-fat milk prepared with Tris-buffered saline containing 0.05\% Tween-20 (TTBS). Subsequently, the membranes were incubated with primary antibodies as the rabbit anti-PAR2, anti-nephrin, anti-TGF- $\beta 1$, anti-caspase-9 and anti-desmin (1:200-1:500, obtained from Neuromics and Abcam Co). After being fully washed, the membrane was incubated with horseradish peroxidase-linked anti-rabbit secondary antibody (1:250) and visualized for immunoreactivity. Likewise, the protein expression of PKA and PKCE was also determined. Rabbit anti-PKCE (1:500) and anti-PKA (1:500) primary antibodies (all obtained from Abcam Co), and goat anti-rabbit secondary antibody (1:250) were applied. The membrane was also processed to detect $\beta$-actin or GADPH for equal loading. The bands recognized by the primary antibody were visualized and the optical densities of protein bands were analyzed using the ImageJ software.

ELISA

The levels of IL-1 $\beta$, IL- 6 and TNF- $\alpha$ were determined using an ELISA assay kit (Promega Corp. Madison, WI) according to the provided description and modification. Briefly, polystyrene 96-well microtitel immunoplates were coated with respective affinity-purified rabbit anti-IL-1 $\beta$, anti-IL- 6 and anti-TNF- $\alpha$ antibodies. Parallel wells were coated with purified rabbit IgG for evaluation of nonspecific signal. After overnight incubation at room temperature and 2 hours of incubation with the coating buffer containing 50 $\mathrm{mM}$ carbonate buffer ( $\mathrm{pH} 9.5$ ) in 2\% BSA, plate were washed with $50 \mathrm{mM}$ Tris- $\mathrm{HCl}$. After extensive washing, the diluted samples and IL-1 $\beta$, IL- 6 and TNF- $\alpha$ standard solution were distributed in each plate, respectively, and left at room temperature overnight. The plates were then washed and incubated with their respective anti-galactosidase per well. Then, the plates were washed and incubated with substrate solution. After an incubation of 2 hours at $37^{\circ} \mathrm{C}$, the optical density was measured using an ELISA reader.

\section{Histopathological examination}

Kidneys from the control rats and ADRN rat were fixed in $10 \%$ formalin solution for 24 hours. After automated dehydration through a graded-alcohol series, transverse kidney slices were embedded in paraffin, sectioned at $3 \mu \mathrm{m}$ and processed with periodic acid-Schiff staining. For the histopathological assessment of glomerular injury a modified form of grading scales (scores of 0-4) was used accordingly to the percentage of glomerular involvement [9]. Three sections per rat were randomly chosen for analysis to obtain averaged data. The sections were analyzed in a blind manner.

\section{Statistical analysis}

All data were analyzed using a two-way repeated-measures analysis of variance. Values were presented as means \pm standard error of mean (SEM). For all analyses, differences were considered significant at $P<$ 0.05. All statistical analyses were performed by using SPSS for Windows version 17.0 (SPSS, USA).

\section{Results}

\section{Expression of PAR2 pathway}

ADR injection significantly increased the protein expression of PAR2 and its downstream pathways, namely PKA and PKCE in the renal tissues (Fig. $1 \mathrm{~A} ; P<0.05$ vs. controls; $n=6$ 8 in each group). Moreover, systemic administration of FSL blocking PAR2 attenuated the exaggerated PKA and $\mathrm{PKC} \varepsilon$ expression in ADRN rats (Fig. $1 \mathrm{~B} ; P<0.05 \mathrm{vs}$. ADRN rats without FSL; $n=6)$ and there was no significant difference observed in the levels of PKA and PKCE between control animals and ADRN rats given with FSL $(P>0.05)$. This result was suggesting effectiveness of FSL used in this study. 
Fig. 1. (A): Top panels and bottom panels represent typical bands and averaged data. Expression of PAR2 and its downstream pathway PKA and PKCe was significantly increased in the renal tissues of ADRN rats as compared with controls. ${ }^{*} P<0.05$ vs. control rats $(\mathrm{n}=6$ 8 in each group). (B): Administration of FSL attenuated the exaggerated PKA and $\mathrm{PKC} \varepsilon$ pathway signals induced by ADR. ${ }^{*} P<0.05$ vs. control rats and ADRN rats with FSL ( $\mathrm{n}=6-8$ in each group). (C): Administration of ADR also amplified the levels of IL-1 $\beta$, IL- 6 and TNF- $\alpha$ in the renal tissues $(n=15)$. Treatment of FSL attenuated the amplified PICs. ${ }^{*} P$ $<0.05$ vs. control rats $(n=15)$ and ADRN rats with FSL $(\mathrm{n}=20)$.

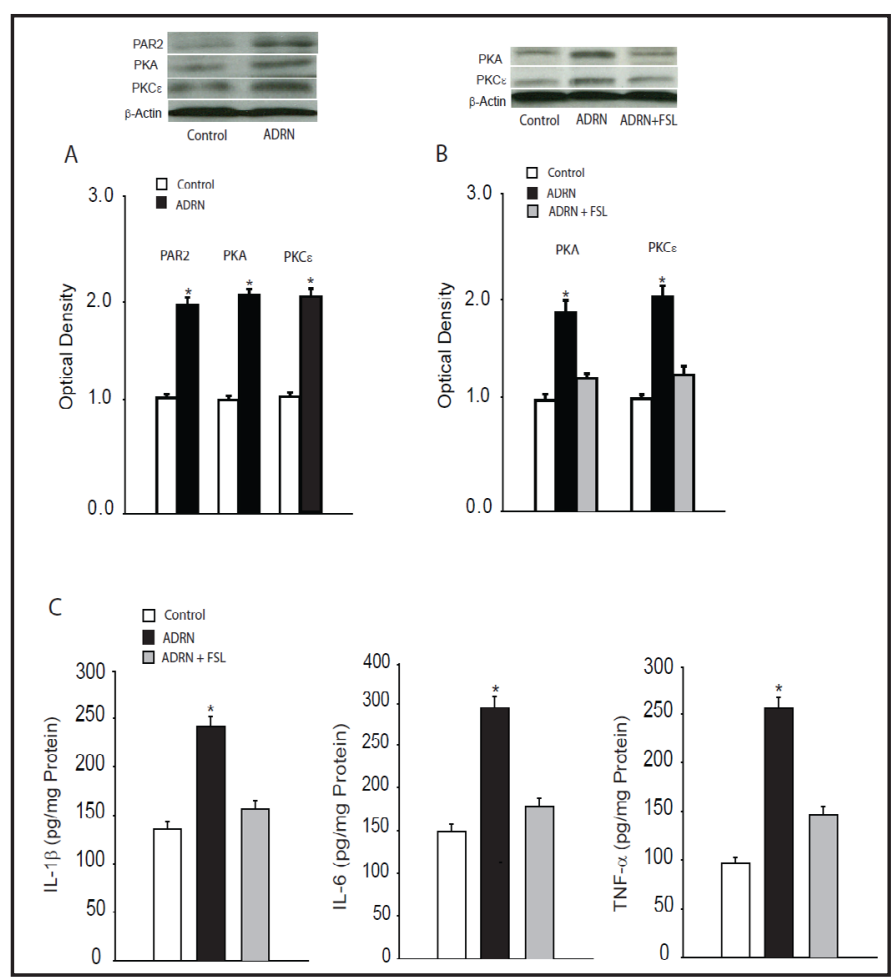

Fig. 2. Effects of ADR on protein expression of nephrin, TGF- $\beta 1$, caspase- 9 and desmin in the renal tissues. Nephrin was decreased in ADRN rats, but TGF- $\beta 1$, caspase- 9 and desmin were upregulated in ADRN rats. The effects of ADR were attenuated after blocking PAR2 using FSL. The top panel and bottom panel are typical bands and averaged data, respectively. ${ }^{*} P<0.05 v s$. control rats and ADRN rats with FSL ( $n=6-8$ in each group).

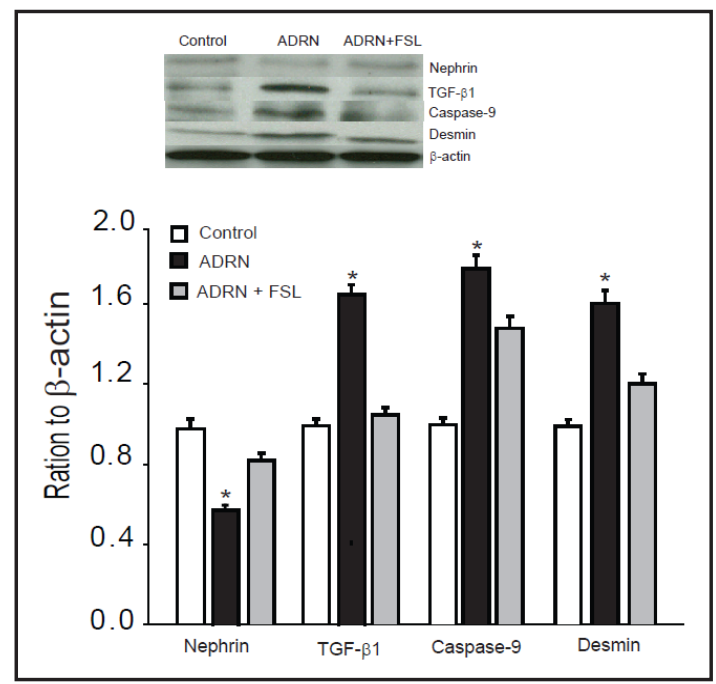

Effects of Blocking PAR2 on Levels of PICs

The levels of IL-1 $\beta$, IL- 6 and TNF- $\alpha$ in three groups of rats are demonstrated (Fig. 1C). Administration of ADR significantly elevated these PIC levels in renal tissues $(P<0.05$ vs. controls; $\mathrm{n}=15$ in each group). Moreover, treatment of FSL significantly attenuated increases of IL-1 $\beta$, IL- 6 and TNF- $\alpha$ evoked by injection of ADR $(n=20)$. Nonetheless, no significant difference in the levels of PICs was observed between control animals and ADRN rats given with FSL $(P>0.05)$.

\section{Effects of Blocking PAR2 on Expression of Mediators Engaged in ADRN}

In order to study the role of PAR2 in the pathophysiological processes of ADRN, we further examined the protein expressions of TGF- $\beta 1$, nephrin, caspase- 9 and desmin in renal tissues of control rats and ADRN rats ( $\mathrm{n}=6-8$ in each group). Figure 2 demonstrates that nephrin was downregulated in ADRN rats $(P<0.05$ vs. control rats $)$ whereas TGF- $\beta 1$, 
Fig. 3. Typical bands (top panel) and averaged data (bottom panel) showing the protein expression levels of nephrin were decreased and desmin and caspase- 9 were increased in cultured TGF- $\beta 1$-treated podocytes. As FSL was applied to inhibit PAR2 signal these changes were diminished. $* P<0.05$ vs. control and $\beta 1$-treated podocytes with FSL treatment.

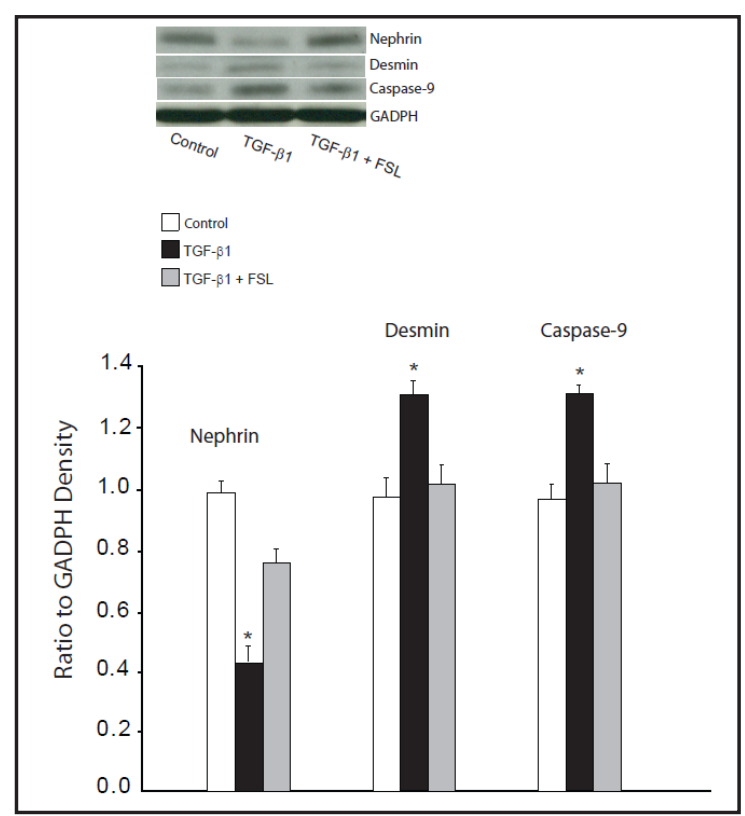

Fig. 4. (A): Sections obtained from renal tissue of three groups of animals. Accumulation of mesangial matrix was observed in tissue of ADRN rats and this was less after using FSL. Original magnification: $\mathrm{x} 400$. (B): Effects of ADR on urinary protein. The levels of urinary protein began to increase 3 weeks after ADR injection and reached to a high level at the sixth week $(\mathrm{n}=15) .{ }^{*} P<$ 0.05 vs. control rats $(n=15)$ and ADRN rats given with FSL $(n=20)$. (C): The ratio of kidney weight (KW) to body weight (BW) and serum creatinine in ADRN rats $(n=15)$ were amplified as compared with control animals $(\mathrm{n}=15)$. Administration of FSL significantly attenuated these abnormalities in ADRN animals $(\mathrm{n}=20) .{ }^{*} P<0.05$ vs. control rats and ADRN rat with treatment of FSL. No significant difference was observed in blood urea nitrogen among three groups.

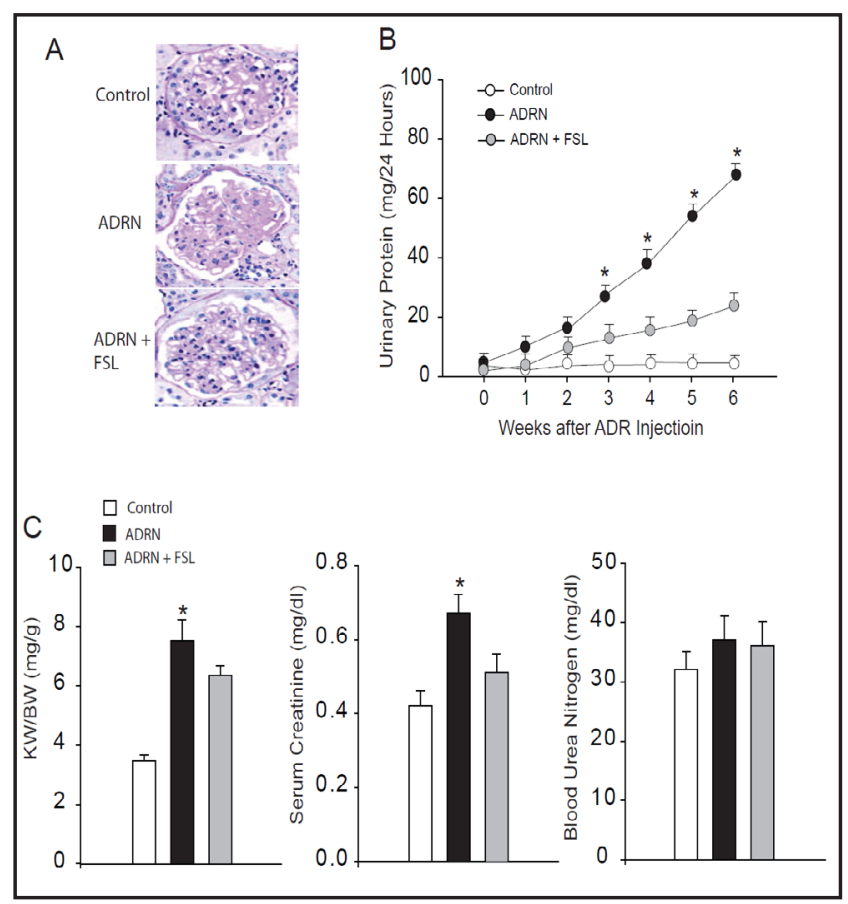

caspase- 9 and desmin were upregulated in ADRN rats $(P<0.05$ vs. control rats for all the proteins). Note that FSL significantly attenuated the effects of ADR on nephrin, TGF- $\beta 1$, caspase- 9 and desmin $(n=6)$. There were no significant differences in these mediators between control animals and ADRN animals that were given with FSL $(P>0.05$ for all the proteins).

Effects of Blocking PAR2 on expression of nephrin, desmin and caspase-9

Figure 3 shows that as compared with the control group, protein expression of nephrin in cultured TGF- $\beta 1$-treated podocytes was decreased $(P<0.05)$, whereas protein expression of desmin and caspase-9 was increased $(P<0.05)$. In addition, FSL significantly attenuated a reduction in nephrin as well as amplifications in desmin and caspase- 9 induced by 48 hours of TGF- $\beta 1$ treatment. 


\section{Effects of Blocking PAR2 on Glomerular Abnormalities}

The renal tissue sections from control rats showed the normal preserved structure. Real tissue of ADRN rat showed glomerular injury. i.e., accumulation of mesangial matrix was observed in tissue of ADRN rats (Fig. 4A). There was a significant increase in the renal injury score in ADRN rats as compared with that of control rats. As FSL was given, the accumulated mesangial matrix injury was greatly improved as indicated by a decrease of injury score $(P<0.05 ; 3.52 \pm 0.35$ in ADRN rats vs. $1.25 \pm 0.22$ in ADRN rats with injection of FSL).

The levels of urinary protein began to significantly increase 3 weeks after ADR injection and reached to a higher level at the sixth week (Fig. 4B; $n=15$ ). Administration of FSL effectively attenuated amplified urinary protein $(P<0.05 v s$. ADRN rats; $n=15$ in ADRN rats and $n=20$ in ADRN rats with FSL). In addition, the ratio of kidney weight to body weight, and serum creatinine were increased in ADRN rats as compared with control animals (Fig. 4C). Systemic administration of FSL significantly improved these abnormalities in ADRN animals.

\section{Discussion}

ADR-induced nephropathy model has been considered as an analogue of human FSGS [10]. Using the same rat model, in the present study we showed that expression of PAR2-PKCE/PKA signal pathway is amplified after application of ADR accompanied with increases of PICs. TGF- $\beta 1$ signaling activity plays a key role in the accumulation of extracellular matrix (ECM) in ADRN [11]. As reported previously [11], our present study also demonstrated upregulation of TGF- $\beta 1$ and that the important molecular mediators engaged in the development of ADRN are altered. Specifically, the protein expression of nephrin is downregulated in ADRN rats, whereas caspase- 9 and desmin are amplified with TGF- $\beta 1$ and PICs. Importantly, these changes are largely reversed by blocking PAR2 in association with the improved abnormalities in urinary protein and serum creatinine of ADRN animals, suggesting the role played by PAR2 signaling in modulating ADRN.

In general, podocytes are the target of injury in chronic glomerular diseases. In these diseases, TGF- $\beta 1$ is secreted by mesangial cells and stored in ECM as latent complexes, and then transported to podocyte surface [12]. On podocytes, TGF- $\beta 1$ binds to its receptor and activates its downstream signaling pathways including Smad, MAPK, ERK and PI3K to modulate the expression of its target genes [13-15]. TGF- $\beta 1$ protein increases in these podocytes with the cellular lesions of FSGS $[13,16]$. It has been reported that TGF- $\beta 1$ reduces podocyte adhesion through $\alpha 3 \beta 1$ integrin downregulation and thus induces podocyte apoptosis [17]. In addition, podocytes undergo apoptosis at early stages in the course of progressive glomerulosclerosis in TGF- $\beta 1$ transgenic mice $[18,19]$. A prior study has demonstrated that local production of TGF- $\beta 1$ leads to the progression of podocyte damage [14]. In the cultured murine podocytes, it was also reported that TGF- $\beta 1$ induces podocyte apoptosis [20]. Consistent with the previous findings, in our current study we observed upregulation of TGF- $\beta 1$ in ADRN animals and this was accompanied with increases of caspase-9 indicating cell apoptosis. Interestingly, we also observed that PAR2 pathway was amplified by ADR and blocking PAR2 signaling attenuated the protein levels of TGF- $\beta 1$ and caspase-9 in ADRN animals. This indicates that PAR2 is likely involved in TGF- $\beta 1$-induced podocyte injury.

Moreover, the apoptosis in TGF- $\beta 1$-treated podocyte is linked to impaired nephrin and upregulated desmin, suggesting that these molecular protein mediators are necessary in involvement of TGF- $\beta 1$ signal engaged in podocyte damage induced by ADR. Results of our current study support this notion because we observed the similar changes of nephrin and desmin in renal tissues of ADRN rats.

Nephrin is a transmembrane protein that is a structural component of the slit diaphragm and necessary for the proper functioning of the renal filtration barrier [21-23]. The renal filtration barrier consists of fenestrated endothelial cells, the glomerular basement membrane, and the podocytes of epithelial cells [21-23]. They are present on the tips of the 
podocytes and maintain the normal relationship between the basement membrane and the podocytes of the epithelial cells. Nephrin regulates a number of pathways in the podocyte, suppresses cell death and apparently forms a complex with podocin [21]. Thus, depletion of nephrin and podocin is associated with degradation of the foot process [21]. A defect in the gene for nephrin, NPHS1, is associated with congenital nephrotic syndrome of the Finnish type and causes massive amounts of protein to be leaked into the urine or proteinuria [24]. Nephrin has also been used as a biomarker for kidney diseases [25]. Many factors inducing podocyte injury increase the levels of nephrin and direct evidence further shows that nephrin is very important in improving podocyte apoptosis of nephropathy including ADRN [26-29]. In our present study, we found that nephrin is impaired in ADRN rats. Inhibition of PAR2 signal can restore the expression levels of nephrin protein and improve urinary protein and serum creatinine of ADRN animals, indicating the crucial role played by PAR2 in mediating podocyte injury induced by ADRN.

Desmin is a type III intermediate filament that integrates the sarcolemma, $\mathrm{Z}$ disk and nuclear membrane in sarcomeresand regulates sarcomere architecture [30]. In adult muscle, desmin forms a scaffold around the Z-disk of the sarcomere and connects the Z-disk to the subsarcolemmal cytoskeleton [31]. It links to the myofibrils laterally by connecting the Z-disks [30]. Through its connection to the sarcomere, desmin connects the contractile apparatus to the cell nucleus, mitochondria, and post-synaptic areas of motor endplates [30]. These connections maintain the structural and mechanical integrity of the cell during contraction while they also help in force transmission and longitudinal load bearing [31, 32]. Upregulated desmin expression is a defense mechanism in maintaining normal sarcomere alignment amidst disease pathogenesis [33]. There is evidence that desmin also connects the sarcomere to the ECM through desmosomes which is likely important in signaling between the ECM and the sarcomere in regulating tissue contraction and movement [32]. Of note, prior studies suggest that desmin is a sensitive marker of podocyte injury [34]. Also, desmin mRNA and protein are increased in cultured mouse podocytes and in vivo study it has been reported that desmin is increased in damaged mouse podocytes by insults of numerous kidney disorders, suggesting that desmin is involved in podocyte injury [35, 36]. Moreover, recovering protein levels of desmin expression play a protective role in regulating injured podocytes [37-39]. Consistent with this notion, in the current study we found that desmin is exaggerated in renal tissues of ADRN rats. Moreover, our findings showed that inhibition of PAR2 signal pathway alleviates the exacerbated expression of desmin.

In the present study, we further examined the effects of PAR2 on podocyte injury in vitro experiments. Results showed that in cultured TGF- $\beta 1$-treated podocytes, nephrin was decreased and caspase- 9 and desmin were increased. Importantly, our data further demonstrated that FSL largely restored downregulation of nephrin induced by TGF- $\beta 1$ in podocytes. Application of FSL also significantly attenuated the amplified protein expression of desmin and caspase- 9 induced by TGF- $\beta 1$ in podocytes. These results are consistent with the data in vivo experiment observed in this report. Nonetheless, our data support the idea that inhibition of PAR2 signal pathway plays a protective role in the process of FSGS. We further provided evidence that podocytes are an important player in mediating the effects of PAR2 signal.

\section{Conclusions}

Results of this study suggest that PAR2 plays an important role in mediating renal injury induced by glomerulosclerosis. Our results further indicate that blocking PAR2 signal pathway has a protective effect on FSGS via PIC and TGF- $\beta 1$ mechanisms, which need involvement of nephrin and desmin. Targeting one or more of these signaling molecules may present new opportunities for treatment and management of FSGS observed in patients. 


\section{Cellular Physiology Cell Physiol Biochem 2017;41:1147-1155 \begin{tabular}{ll|l} 
and Biochemistry & $\begin{array}{l}\text { DOI: 10.1159/000464121 } \\
\text { Published onlne: February 28, } 2017\end{array}$ & $\begin{array}{l}\text { O 2017 The Author(s). Published by S. Karger AG, Basel } \\
\text { www.karger.com/cpb }\end{array}$ \\
\cline { 2 - 3 }
\end{tabular}}

Wang et al.: PAR2 Signaling and Renal Fibrosis

\section{Disclosure Statement}

None.

\section{References}

1 Sweetwyne MT, Tao J, Susztak K: Kick it up a notch: Notch signaling and kidney fibrosis. Kidney Int Suppl (2011) 2014;4:91-96.

2 Duffield JS: Cellular and molecular mechanisms in kidney fibrosis. J Clin Invest 124:2299-2306.

-3 Schnaper HW: Renal fibrosis. Methods Mol Med 2005;117:45-68.

-4 Cottrell GS, Amadesi S, Schmidlin F, Bunnett N: Protease-activated receptor 2: activation, signalling and function. Biochem Soc Trans 2003;31:1191-1197.

-5 Adams MN, Ramachandran R, Yau MK, Suen JY, Fairlie DP, Hollenberg MD, Hooper JD: Structure, function and pathophysiology of protease activated receptors. Pharmacol Ther 2011;130:248-282.

6 Dulon S, Cande C, Bunnett NW, Hollenberg MD, Chignard M, Pidard D: Proteinase-activated receptor-2 and human lung epithelial cells: disarming by neutrophil serine proteinases. Am J Respir Cell Mol Biol 2003;28:339-346.

7 Ramachandran R, Mihara K, Chung H, Renaux B, Lau CS, Muruve DA, DeFea KA, Bouvier M, Hollenberg MD: Neutrophil elastase acts as a biased agonist for proteinase-activated receptor-2 (PAR2). J Biol Chem 2011;286:24638-24648.

-8 Wan YG, Che XY, Sun W, Huang YR, Meng XJ, Chen HL, Shi XM, Tu Y, Wu W, Liu YL: Low-dose of multiglycoside of Tripterygium wilfordii Hook. f., a natural regulator of TGF-beta1/Smad signaling activity improves adriamycin-induced glomerulosclerosis in vivo. J Ethnopharmacol 2014;151:1079-1089.

-9 Raij L, Azar S, Keane W: Mesangial immune injury, hypertension, and progressive glomerular damage in Dahl rats. Kidney Int 1984;26:137-143.

-10 Lee VW, Harris DC: Adriamycin nephropathy: A model of focal segmental glomerulosclerosis. Nephrology 2011;16:30-38.

11 Li J, Campanale NV, Liang RJ, Deane JA, Bertram JF, Ricardo SD: Inhibition of p38 mitogen-activated protein kinase and transforming growth factor-beta1/Smad signaling pathways modulates the development of fibrosis in adriamycin-induced nephropathy. Am J Pathol 2006;169:1527-1540.

12 Lee HS, Song CY: Differential role of mesangial cells and podocytes in TGF-beta-induced mesangial matrix synthesis in chronic glomerular disease. Histol Histopathol 2009;24:901-908.

13 Kim TS, Kim JY, Hong HK, Lee HS: mRNA expression of glomerular basement membrane proteins and TGFbeta1 in human membranous nephropathy. J Pathol 1999;189:425-430.

14 Massague J, Blain SW, Lo RS: TGFbeta signaling in growth control, cancer, and heritable disorders. Cell 2000;103:295-309.

15 Schiffer M, Mundel P, Shaw AS, Bottinger EP: A novel role for the adaptor molecule CD2-associated protein in transforming growth factor-beta-induced apoptosis. J Biol Chem 2004;279:37004-37012.

16 Patek CE, Fleming S, Miles CG, Bellamy CO, Ladomery M, Spraggon L, Mullins J, Hastie ND, Hooper ML: Murine Denys-Drash syndrome: evidence of podocyte de-differentiation and systemic mediation of glomerulosclerosis. Hum Mol Genet 2003;12:2379-2394.

17 Dessapt C, Baradez MO, Hayward A, Dei Cas A, Thomas SM, Viberti G, Gnudi L: Mechanical forces and TGFbeta1 reduce podocyte adhesion through alpha3beta1 integrin downregulation. Nephrol Dial Transplant 2009;24:2645-2655.

18 Kopp JB, Factor VM, Mozes M, Nagy P, Sanderson N, Bottinger EP, Klotman PE, Thorgeirsson SS: Transgenic mice with increased plasma levels of TGF-beta 1 develop progressive renal disease. Lab Invest 1996;74:991-1003.

19 Sanderson N, Factor V, Nagy P, Kopp J, Kondaiah P, Wakefield L, Roberts AB, Sporn MB, Thorgeirsson SS: Hepatic expression of mature transforming growth factor beta 1 in transgenic mice results in multiple tissue lesions. Proc Natl Acad Sci U S A 1995;92:2572-2576.

20 Schiffer M, Bitzer M, Roberts IS, Kopp JB, ten Dijke P, Mundel P, Bottinger EP: Apoptosis in podocytes induced by TGF-beta and Smad7. J Clin Invest 2001;108:807-816. 


\section{Cellular Physiology Cell Physiol Biochem 2017;41:1147-1155 \begin{tabular}{ll|l} 
DOI: 10.1159/000464121 & 2017 The Author(s). Published by S. Karger AG, Basel \\
and Biochemistry Publisned online: February 28, 2017 & \begin{tabular}{l} 
www.karger.com/cpb \\
\cline { 2 - 3 }
\end{tabular}
\end{tabular}}

Wang et al.: PAR2 Signaling and Renal Fibrosis

21 Huber TB, Kottgen M, Schilling B, Walz G, Benzing T: Interaction with podocin facilitates nephrin signaling. J Biol Chem 2001;276:41543-41546.

22 Lehtonen S, Lehtonen E, Kudlicka K, Holthöfer H, Farquhar MG: Nephrin Forms a Complex with Adherens Junction Proteins and CASK in Podocytes and in Madin-Darby Canine Kidney Cells Expressing Nephrin. Am J Pathol 165:923-936.

23 Yuan H, Takeuchi E, Salant DJ: Podocyte slit-diaphragm protein nephrin is linked to the actin cytoskeleton. Am J Physiol Renal Physiol 2002;282:F585-591.

-24 Wagner N, Morrison H, Pagnotta S, Michiels JF, Schwab Y, Tryggvason K, Schedl A, Wagner KD: The podocyte protein nephrin is required for cardiac vessel formation. Hum Mol Genet 2011;20:2182-2194.

-25 Perez-Hernandez J, Olivares MD, Forner MJ, Chaves FJ, Cortes R, Redon J: Urinary dedifferentiated podocytes as a non-invasive biomarker of lupus nephritis. Nephrol Dial Transplant DOI:10.1093/ndt/ gfw002.

26 Jeong KH, Asanuma K, Lydia A, Takagi M, Asao R, Kodama F, Asanuma E, Tomino Y: Combination therapy with telmisartan and oxacalcitriol suppresses the progression of murine adriamycin nephropathy. Nephron 2015;129:143-154.

27 Li X, Chuang PY, D'Agati VD, Dai Y, Yacoub R, Fu J, Xu J, Taku O, Premsrirut PK, Holzman LB, He JC: Nephrin Preserves Podocyte Viability and Glomerular Structure and Function in Adult Kidneys. J Am Soc Nephrol 2015;26:2361-2377.

28 Yang H, Wang Q, Li S: MicroRNA-218 promotes high glucose-induced apoptosis in podocytes by targeting heme oxygenase-1. Biochem Biophys Res Commun 2016;471:582-588.

29 Yu J, Gong W, Wu Y, Li S, Cui Y, Ma Y, Zhang Y, Yang G, Huang S, Jia Z, Zhang A: mPGES-1-derived PGE2 contributes to adriamycin-induced podocyte injury. Am J Physiol Renal Physiol 2016;310:F492-498.

-30 Bär H, Strelkov SV, Sjöberg G, Aebi U, Herrmann H: The biology of desmin filaments: how do mutations affect their structure, assembly, and organisation? J Struct Biol 2004;148:137-152.

-31 Paulin D, Li Z: Desmin: a major intermediate filament protein essential for the structural integrity and function of muscle. Exp Cell Res 2004;301:1-7.

-32 Shah SB, Davis J, Weisleder N, Kostavassili I, McCulloch AD, Ralston E, Capetanaki Y, Lieber RL: Structural and Functional Roles of Desmin in Mouse Skeletal Muscle during Passive Deformation. Biophys J 86:29933008.

33 Heling A, Zimmermann R, Kostin S, Maeno Y, Hein S, Devaux B, Bauer E, Klovekorn WP, Schlepper M, Schaper W, Schaper J: Increased expression of cytoskeletal, linkage, and extracellular proteins in failing human myocardium. Circ Res 2000;86:846-853.

34 Kakimoto T, Okada K, Hirohashi Y, Relator R, Kawai M, Iguchi T, Fujitaka K, Nishio M, Kato T, Fukunari A, Utsumi H: Automated image analysis of a glomerular injury marker desmin in spontaneously diabetic Torii rats treated with losartan. J Endocrinol 2014;222:43-51.

-35 Floege J, Kriz W, Schulze M, Susani M, Kerjaschki D, Mooney A, Couser WG, Koch KM: Basic fibroblast growth factor augments podocyte injury and induces glomerulosclerosis in rats with experimental membranous nephropathy. J Clin Invest 1995;96:2809-2819.

-36 Zhang C, Hu JJ, Xia M, Boini KM, Brimson C, Li PL: Redox signaling via lipid raft clustering in homocysteineinduced injury of podocytes. Biochim Biophys Acta 2010;1803:482-491.

- 37 Eto N, Wada T, Inagi R, Takano H, Shimizu A, Kato H, Kurihara H, Kawachi H, Shankland SJ, Fujita T, Nangaku M: Podocyte protection by darbepoetin: preservation of the cytoskeleton and nephrin expression. Kidney Int 2007;72:455-463.

38 Huang F, Wang Q Ma X, Wu L, Guo F, Qin G: Valsartan inhibits amylin-induced podocyte damage. Microvasc Res 2016;106:101-109.

- 39 Zuo Y, Yang HC, Potthoff SA, Najafian B, Kon V, Ma LJ, Fogo AB: Protective effects of PPARgamma agonist in acute nephrotic syndrome. Nephrol Dial Transplant 2012;27:174-181. 